\title{
A New Methodology to Preliminary Design Structural Components of Re-Entry and Hypersonic Vehicles
}

\author{
Michele Ferraiuolo ${ }^{1}$ and Oronzio Manca ${ }^{2}$ \\ 1CIRA-Italian Aerospace Research Centre \\ 2Seconda Università di Napoli \\ Italy
}

\section{Introduction}

The aim of the hot structure design process is to ensure the structural integrity of the component minimizing two fundamental parameters: mass and thickness. The former influences the total weight of the vehicle, the latter influences the vehicle efficiency (Thornton, 1996;Kelly et al, 1983; Shih et al, 1988).

In order to perform the thermo-structural sizing of the component it is necessary to evaluate the stress and temperature distribution. Usually numeric methods (finite element or finite difference codes) are adopted to estimate those distribution (Daryabeigi, 2002;Poteet et al, 2004). In a preliminary design phase where accurate results are not required, approximate analytic solutions can be used (Kunihiko, 1998).

Analytic solutions, whether exact or approximate, are always useful in engineering analysis, because they provide a better insight into the physical significance of various parameters affecting the problem. When exact analytic solutions are impossible or too difficult to obtain or the resulting analytic solutions are too complicated for computational purposes, approximate analytic solutions provide a powerful alternative approach to handle such problems. There are numerous approximate analytic methods for solving the partial differential equations governing the engineering problems. One of the most powerful method is the Integral one (Crank, 1979; Syed et al, 2010). It is simple to use and gives the opportunity to solve non linear problems such as thermal radiation/conduction ones.

In the frame of thermal structures preliminary design activities the adoption of the integral method together with appropriate assumptions give the possibility to develop analytic/numeric models that allow to solve non linear transient thermal phenomena. Those methods are very useful since they are very simple to use and allow to save a significant amount of time with respect to numeric Finite Element models in a thermal structure preliminary design phase. As a consequence, complex optimization analyses characterized by several design objectives, constraints and variables in a reasonable length of time could be conducted. The proposed approach allows to define a preliminary thermal design of the hot structure. Obviously, in a subsequent design phase structural sizing must be performed starting from the configuration resulted from the previous thermal sizing process.

The present paper describes in detail how the proposed model works. An application of the simplified model on the wing leading edge of a re-entry vehicle is presented. 


\section{Description of the method}

\subsection{Integral method}

The integral method is an approximated analytical method since it is based on the assumption that the temperature distribution is described by a chosen expression (polynomial, logarithmic, etc.) (Necati, Ozisik, 1993).

The method is simple, straightforward, and easily applicable to both linear and nonlinear one-dimensional transient boundary value problems of heat conduction for certain boundary conditions. The results are approximate, but several solutions obtained with this method when compared with exact solutions have confirmed that the accuracy is generally acceptable for many engineering applications. In general when the differential equation of heat conduction is solved exactly in a given region subject to specified boundary and initial conditions, the resulting solution is satisfied at each point over the considered region; but with the integral method the solution is satisfied only on the average over the region.

The heat conduction equation is integrated over the spatial domain of the body; the result of the integration is the so called "energy integral equation". An appropriate expression for the temperature distribution is chosen; the coefficients of the temperature expression are function of the boundary conditions. Then the temperature expression is introduced in the integral equation; its solution gives the temperature variation with time. Once temperature variation with time is available, $T(x, t)$ is known.

The use of the integral method can be divided into two sequential stages.

1. Approximation of semi-infinite body. It is valid when the thermal layer $\delta(t)$, that is the distance beyond which there is no heat flux, is less than the body thickness.

2. $\delta(t)>$ L. The concept of thermal layer has no physical significance. Starting from the solution of the first stage, the heat conduction equation is integrated over the body thickness.

Several applications of the integral method have been found in literature. However none of them considers non linear boundary conditions and thermal properties.

\subsection{Proposed model}

In order to take into account the heat flux variation with time and thermal properties variation with temperature it is necessary to divide the trajectory time into a chosen number of time steps. The choice is such that the heat flux variation in a single time step must be less or equal than $1 \%$ of the maximum heat flux encountered during the flight trajectory, that is:

$$
\left|q_{w}\left(t_{i+1}\right)-q_{w}\left(t_{i}\right)\right|<0.01 \cdot q_{w, \max }
$$

Where:

- $\quad t i$ is the ith time instant at the beginning of the ith time step

- $t i+1$ is the $i+1$ th time instant at the end of the ith time step

- $\mathrm{qw}$ is the aerodynamic heating

- $\quad$ qw,max is the maximum aerodynamic heating value

The aerodynamic heat flux value is considered constant in the ith time step and equal to the algebraic mean value between the heat flux values encountered at the ith and $i+1$ th time instants:

$$
0.5 \cdot\left[q_{w}\left(t_{i}\right)+q_{w}\left(t_{i+1}\right)\right]
$$


$\overline{t_{i}}$ is the ith time step.

Thermal conductivity $\mathrm{k}$ and specific heat $\mathrm{cp}$ values are considered constant and equal to:

$$
\begin{gathered}
k=k\left(T_{i}\right) \\
c_{p}=c_{p}\left(T_{i}\right)
\end{gathered}
$$

Where $\mathrm{Ti}$ is the temperature evaluated at the end of the $\mathrm{i}-1$ th time step.

In the first stage (approximation of semi-infinite body), radiation contribution is neglected, then linear boundary conditions are applied. In the ith time step the heat conduction differential equation is integrated between $\delta_{i}$ and $\delta_{i+1}$, that is thermal layer values respectively at $t_{i}$ and $t_{i+1}$ time instants.

$$
\int_{\delta_{i}}^{\delta_{i+1}} \frac{\partial^{2} T}{\partial x^{2}} d x=\frac{1}{\alpha} \int_{\delta_{i}}^{\delta_{i+1}} \frac{\partial T}{\partial t} d x
$$

The boundary and initial conditions to be applied are:

$$
\begin{aligned}
& T\left(x_{1}=\delta_{i}\right)=T_{i n} \\
& -k \cdot \frac{\partial T}{\partial x}(x=0)=q_{w} \\
& \frac{\partial T}{\partial x}\left(x=\delta_{i+1}\right)=0
\end{aligned}
$$

Where $T_{i n}$ is the initial temperature. A further condition may be derived by evaluating the heat conduction differential equation at $\mathrm{x}=\delta_{i+1}$ where $T=T$ in $=$ constant.

$$
\frac{\partial^{2} T}{\partial x^{2}}\left(x=\delta_{i+1}\right)=0
$$

Since the time parameter to be evaluated in the integral equation is the thermal layer $\delta_{i+1}(t)$ and since the available conditions for the thermal problem are 4 (see Eq. (6) and (7)), then a polynomial expression with more than 4 parameters cannot be selected. As a consequence, the temperature profile chosen is a cubic one:

$$
T(x, t)=a+b \cdot x+c \cdot x^{2}+d \cdot x^{3}
$$

The parameters $a, b, c$ and $d$ are functions of $\delta_{i+1}(t)$. Once the conditions (6) and (7) are applied and the ordinary differential integral Eq. (5) is solved, the temperature distribution $T(x, t)$ is known.

Figure 1 illustrates the physical significance of the "thermal layer".

The energy integral equation is:

$$
-\alpha \cdot \frac{\partial T}{\partial x}(x=0)=\frac{d}{d t}\left(\theta-T_{i} \cdot \delta_{i}\right)
$$




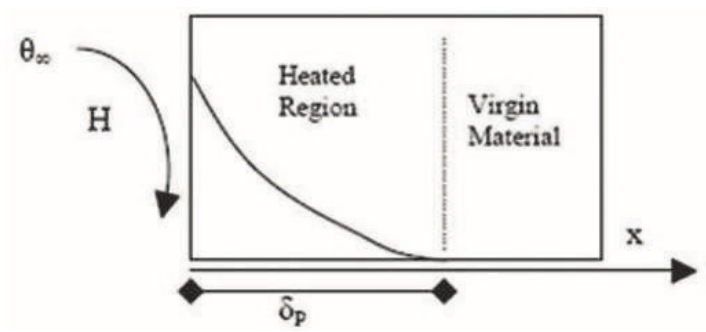

Fig. 1. Physical significance of thermal layer

Where:

$$
\theta=\int_{\delta_{i}}^{\delta_{i+1}} T(x, t) d x
$$

Then the temperature distribution $\mathrm{T}(\mathrm{x}, \mathrm{t})$ is known:

$$
\begin{aligned}
& T(x, t)=T_{i}+\frac{q_{w}}{3 \cdot k} \cdot\left(\delta_{i+1}(t)-\delta_{i}(t)\right)-\frac{q_{w}}{k} \cdot x+ \\
& +\frac{q_{w}}{k \cdot\left(\delta_{i+1}(t)-\delta_{i}(t)\right)} \cdot x^{2}-\frac{q_{w}}{3 \cdot k \cdot\left(\delta_{i+1}^{2}(t)-\delta_{i}^{2}(t)\right)} \cdot x^{3}
\end{aligned}
$$

Where:

$$
\begin{gathered}
\delta_{i}=\sqrt{12 \cdot \alpha \cdot t_{i}} \\
\delta_{i+1}=\sqrt{12 \cdot \alpha \cdot t_{i+1}}
\end{gathered}
$$

When $\delta(t)$ is greater than the thickness L, the semi-infinite body approximation cannot be considered. The heat conduction differential equation is integrated over the thickness L:

$$
\int_{0}^{L} \frac{\partial^{2} T}{\partial x^{2}} d x=\int_{0}^{L} \frac{1}{\alpha} \frac{\partial T}{\partial t} d x
$$

Giving the following energy integral equation:

$$
\frac{\partial T}{\partial x}(x=L)-\frac{\partial T}{\partial x}(x=0)=\frac{1}{\alpha} \cdot \frac{d}{d t}\left(\theta-T_{i} \cdot L\right)
$$

The origin of the $x$ axis is on the external surface where aerodynamic heating is applied. At $\mathrm{x}=\mathrm{L}$ adiabatic boundary conditions are considered (see figure 2).

The boundary conditions are:

$$
\begin{aligned}
& -k \cdot \frac{\partial T}{\partial x}(x=0)=q_{w}-\sigma \cdot \varepsilon \cdot\left(T_{s}(t)^{4}-T_{e}(t)^{4}\right) \\
& \frac{\partial T}{\partial x}(x=L)=0
\end{aligned}
$$




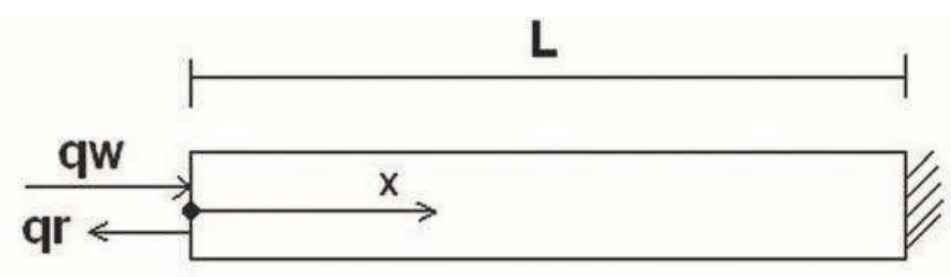

Fig. 2. Schematic representation of the thermal problem

Where Te is the ambient temperature and Ts is the temperature at $\mathrm{x}=0$.

For the same arguments explained above, the temperature distribution chosen is a quadratic one:

$$
T(x, t)=a+b \cdot x+c \cdot x^{2}
$$

As mentioned before the thermal layer has now no physical significance. Then it is necessary to introduce a new time-dependent parameter. Two kind of parameters can be considered:

1. $\operatorname{Ts}(\mathrm{t})$

2. $\quad \bar{r}=\operatorname{Ts}(\mathrm{t})+\mathrm{TL}(\mathrm{t})$

Where TL $(\mathrm{t})$ is the temperature at $\mathrm{x}=\mathrm{L}$.

In paragraph 2 it will be demonstrated that the second approach gives better results with respect to the first one when compared to one-dimensional finite element model results. In fact, in the second approach the solution of the energy integral equation has an information on the temperature distribution of the previous time step since the parameter $\bar{r}$ represents the sum of the temperature values at the extreme points of the body. On the contrary in the first approach it is not possible to give any information on the previous temperature distribution.

The energy integral equation is:

$$
-\alpha \cdot \frac{\partial T}{\partial x}(x=0)=\frac{d}{d t}\left(\theta-T_{i} \cdot L\right)
$$

Where:

$$
\theta=\int_{0}^{L} T(x, t) d x
$$

When boundary conditions are applied, the integral equation becomes:

$$
\left(A+B \cdot T_{s}(t)^{3}\right) \cdot \frac{d T_{s}}{d t}+C \cdot T_{s}(t)^{4}=D
$$

For the second case:

$$
\left(A+B \cdot \bar{r}(t)^{3}\right) \cdot \frac{\overline{d r}}{d t}+C \cdot \bar{r}(t)^{4}=D
$$


The terms $B \cdot T_{s}(t)^{3}$ and $B \cdot \bar{r}(t)^{3}$ are neglected when:

$$
\frac{4}{3} \frac{\sigma \varepsilon}{k} T_{s}^{3} L<<<1
$$

Where $\sigma$ is the Stefan-Boltzmann constant, $\varepsilon$ is the surface emissivity. The terms A, B, C and $\mathrm{D}$ are thermal properties and heat flux functions. The temperature expressions for the two cases are respectively:

$$
\begin{aligned}
& T(x, t)=T_{s}(t)+\left[\frac{\sigma \cdot \varepsilon \cdot\left(T_{s}(t)^{4}-T_{e}^{4}\right)}{k}-\frac{q_{w}}{k}\right] \cdot x+ \\
& +\left[\frac{q_{w}}{2 \cdot L \cdot K}-\frac{\sigma \cdot \varepsilon \cdot\left(T_{s}(t)^{4}-T_{e}^{4}\right)}{2 \cdot L \cdot k}\right] \cdot x^{2} \\
& T(x, t)=\frac{\bar{r}}{2}-\frac{1}{4 k}\left[q_{w}-\sigma \varepsilon\left(\frac{\bar{r}}{2}\right)^{4}\right]+ \\
& +\frac{1}{k}\left[\sigma \varepsilon\left(\frac{\bar{r}}{2}\right)^{4}-q_{w}\right] \cdot x-\frac{1}{2 L k}\left[\sigma \varepsilon\left(\frac{\bar{r}}{2}\right)^{4}-q_{w}\right] \cdot x^{2}
\end{aligned}
$$

Following the same approach and changing adequately the boundary conditions it is possible to take into account the heat radiation exchange with an internal structure (see figure 3).

In particular, the first expression in (16) becomes:

$$
\frac{4}{3} \frac{\sigma \varepsilon}{k} T_{s}^{3} L<<1
$$

Where $T_{M}$ represents the external surface temperature of the internal structure. The temperature distribution inside the internal structure is evaluated following the same approach described for the hot structure in a radiative environment; in this case the aerodynamic heating is substituted with the heat radiation flowing from the hot structure. The final expression for the temperature distribution in the hot structure is:

$$
\begin{aligned}
& T(x, t)=\frac{\bar{r}}{2}-\frac{L}{2 k}\left[\sigma \varepsilon_{1}(r / 2)^{4}-\sigma \varepsilon_{1}\left(T_{r}\right)^{4}-q_{w}\right] \\
& -\frac{L}{4 k}\left[\sigma\left(\varepsilon_{1}+\varepsilon_{2}\right)(r / 2)^{4}-\sigma \varepsilon_{1}\left(T_{r}\right)^{4}-q_{w}\right]+ \\
& +\frac{1}{k}\left[\sigma \varepsilon_{1}(r / 2)^{4}-\sigma \varepsilon_{1}\left(T_{r}\right)^{4}-q_{w}\right] x+ \\
& -\frac{1}{2 L k}\left[\sigma\left(\varepsilon_{1}+\varepsilon_{2}\right)(r / 2)^{4}-\sigma \varepsilon_{1}\left(T_{r}\right)^{4}-q_{w}\right] x^{2}
\end{aligned}
$$

Where $\varepsilon_{1}$ is the external emissivity and $\varepsilon_{2}$ is the internal emissivity. The model can be also applied to double-layer structures. 


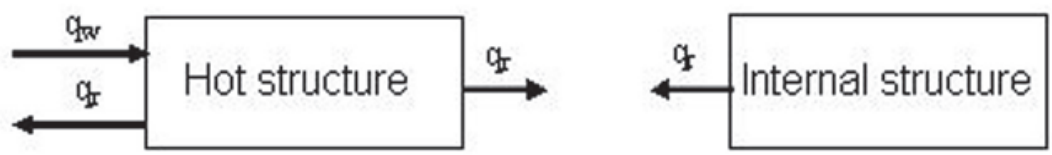

Fig. 3. Schematic representation of the thermal problem-internal radiation

\subsection{Comparison with Finite Element results}

The model described in the previous paragraph has been validated comparing the results of a one-dimensional thermal problem obtained with the proposed model with the results obtained with the Finite Element method. The Finite Element Analyses have been performed on one-dimensional conduction bars LINK32 elements that simulate the heat conduction phenomenon between two nodes (Ansys 12.0). The element is characterized by a single degree of freedom (temperature), the thermal properties and the cross sectional area. The external radiation has been simulated by means of LINK31 elements that are characterized by two nodes, a view factor, emissivity and the Stefan-Boltzmann constant. The net heat radiation between node I and node $\mathrm{J}$ is defined by equation (26):

$$
q_{r}=\sigma \varepsilon F A\left[T(I)^{4}-T(J)^{4}\right]
$$

A convergence analysis has been conducted on the mesh of the finite element model.

The benchmark is characterized by the following properties:

$$
\begin{gathered}
\rho=5000 \mathrm{~kg} / \mathrm{m}^{3} \\
L=0.05 \mathrm{~m}
\end{gathered}
$$

Where $\rho$ is the density and $\mathrm{L}$ is the slab thickness. The thermal conductivity $k$ and the specific heat $c_{p}$ variations with time are illustrated in figures 4 and 5 .

\section{Thermal conductivity vs Temperature}

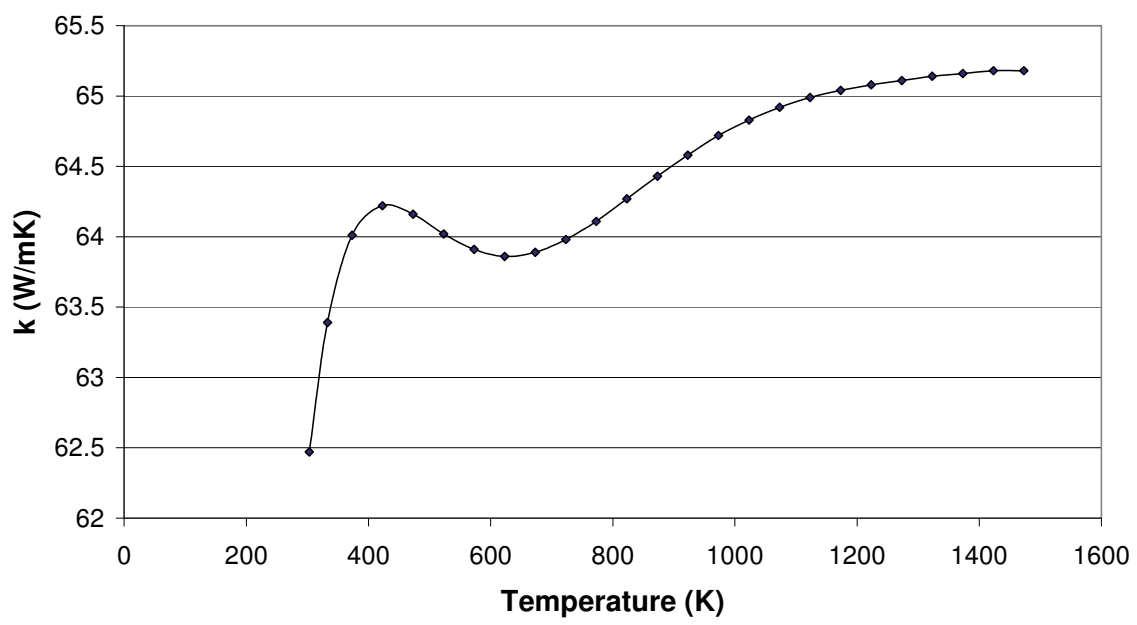

Fig. 4. UHTC Thermal conductivity vs Temperature 


\section{Specific Heat vs Temperature}

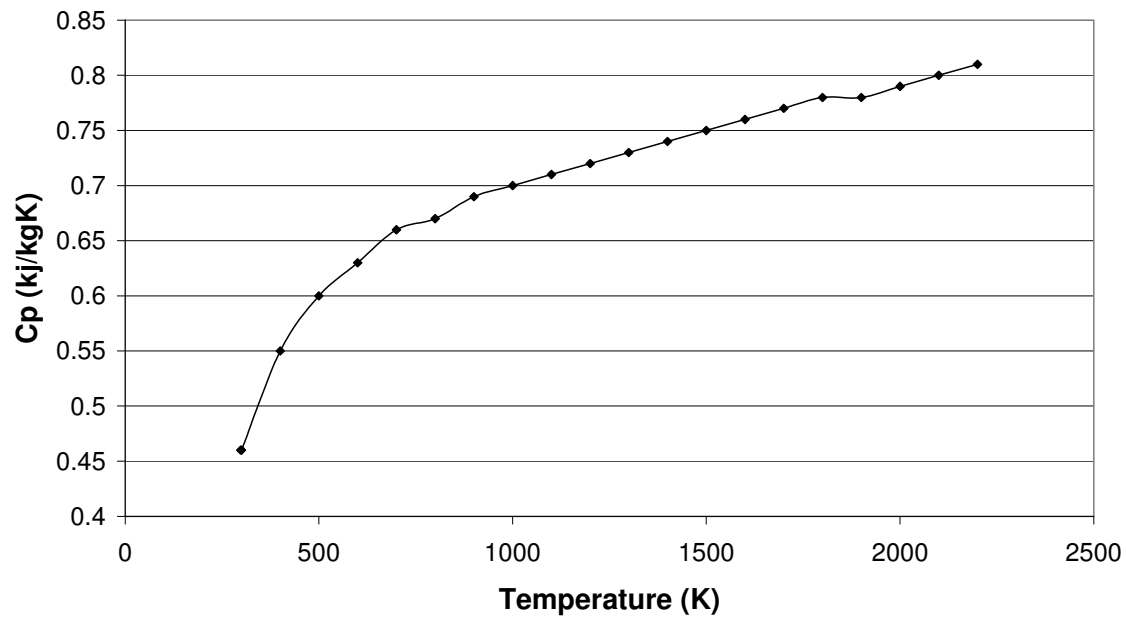

Fig. 5. UHTC Specific Heat vs Temperature

The aerodynamic heating variation with time is depicted in figure 6.

\section{Aerodynamic heating vs time}

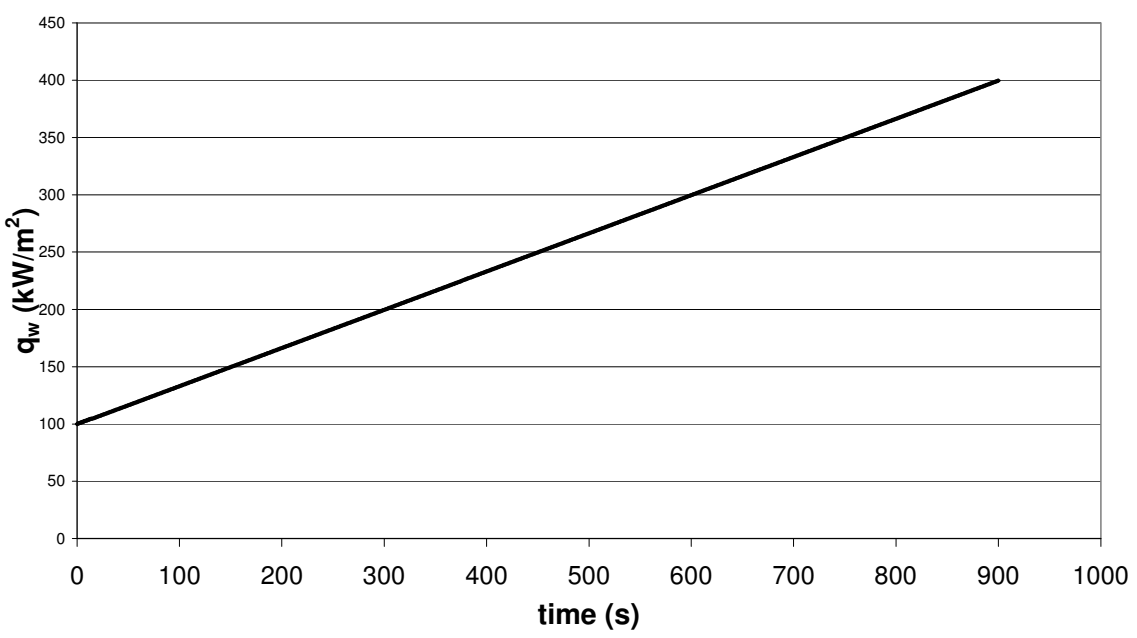

Fig. 6. Aerodynamic heating vs time

The temperature of the external environment is considered constant and equal to:

$$
\mathrm{Te}=300 \mathrm{~K}
$$

The initial temperature of the structure is:

$$
\mathrm{Ti}=300 \mathrm{~K}
$$


Figure 7 shows the location of the points of the structure that will be considered for the results comparison.

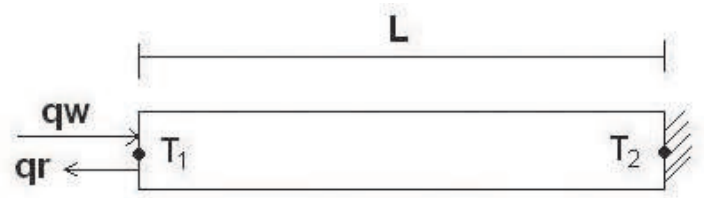

Fig. 7. Position of the points considered for the validation

Figures 8 and 9 illustrate T1 and T2 variations with time. The labels "I model" and "II model" refer respectively to the results obtained considering $r(t)$ and $T_{1}(t)$ as time parameters.

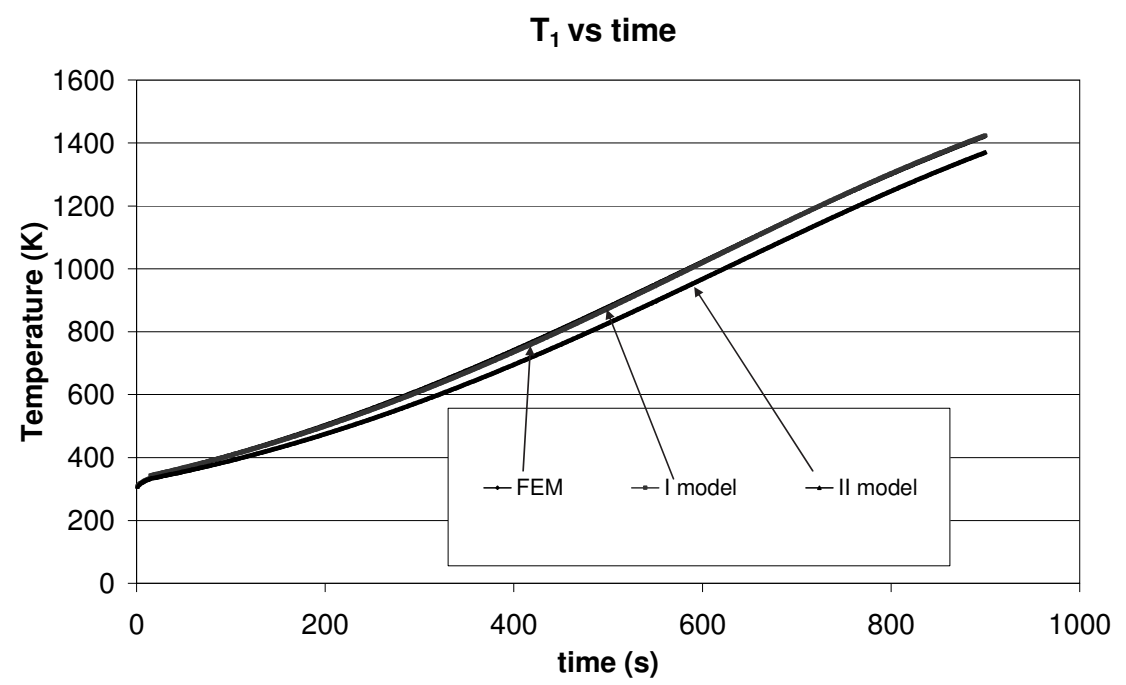

Fig. 8. Temperature $\mathrm{T}_{1}$ vs time

A good accordance between the FEM and the I model results is recorded. The maximum percentage difference is $15.7 \%$ (see also figure 9 and 10). On the contrary the second model curve is characterized by significantly greater differences with respect to the FEM results (see figure 10 and table 1); this means that the adoption of a parameter that gives precious information regarding the previous temperature distribution is fundamental in order to evaluate the temperature distribution.

Figures 9 and 10 show that the maximum percentage difference occurs after about 50 seconds; more precisely it occurs when the passage from the semi-infinite body approximation to the finite body approximation. This is due to the different temperature distributions chosen for the two solutions (third order polynomial for the semi-infinite body, second order polynomial for the finite body). 


\section{$\mathrm{T}_{2}$ vs time}

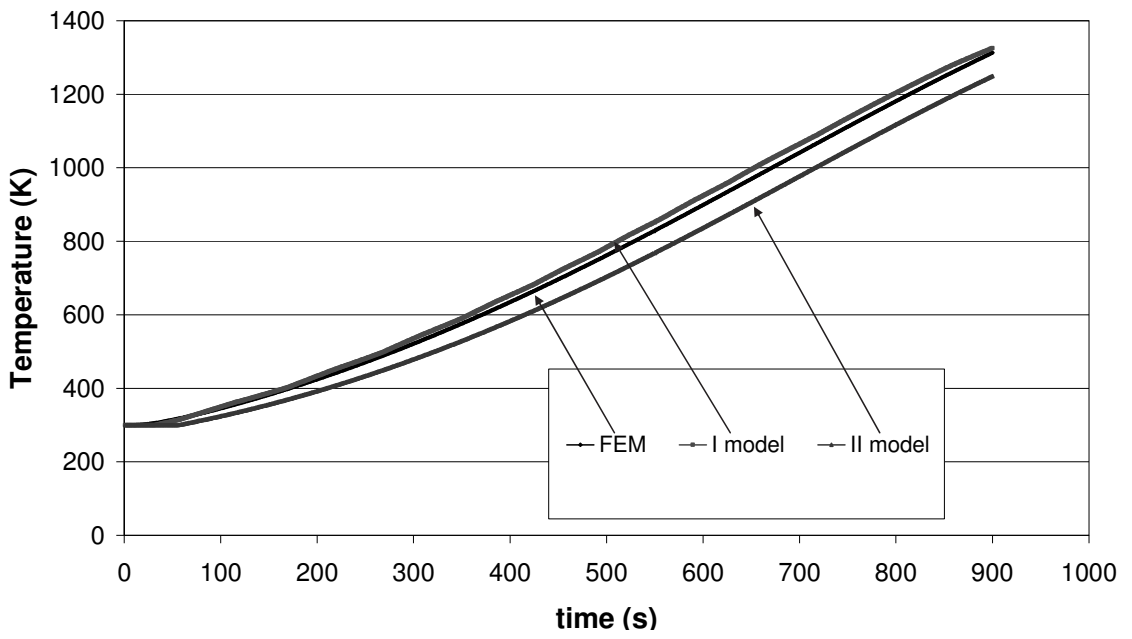

Fig. 9. Temperature $T_{2}$ vs time

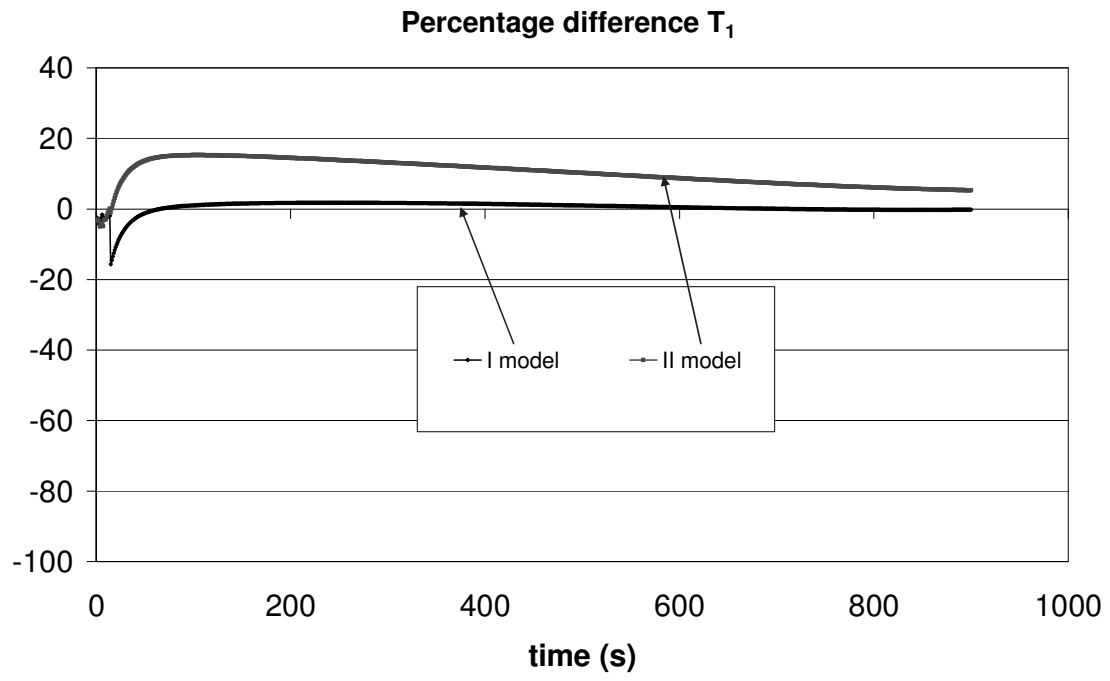

Fig. 10. Percentage difference-Temperature $T_{1}$ vs time 


\section{Percentage difference $T_{2}$}

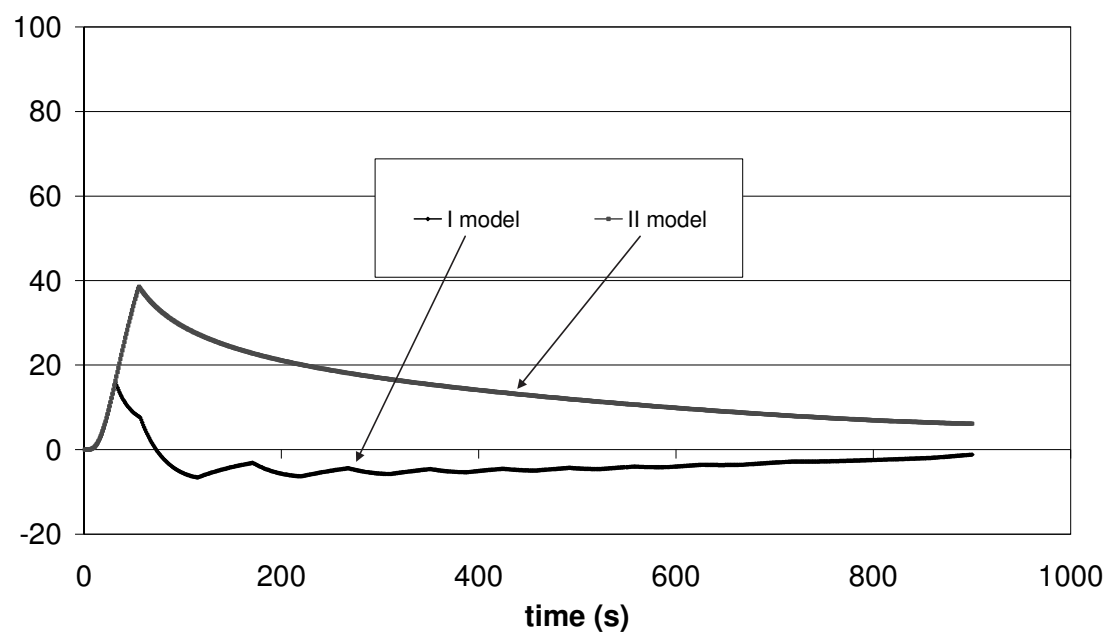

Fig. 11. Percentage difference-Temperature $\mathrm{T}_{2}$ vs time

The same remarks can be made for the temperature $T_{2}$. The percentage differences are slightly greater (see table 1).

\begin{tabular}{|c|c|c|}
\hline & $\mathrm{T}_{1}$ & $\mathrm{~T}_{2}$ \\
\hline $\begin{array}{c}\mathrm{I} \\
\text { model }\end{array}$ & $15.7 \%$ & $16 \%$ \\
\hline $\begin{array}{c}\mathrm{II} \\
\text { model }\end{array}$ & $-18 \%$ & $39 \%$ \\
\hline
\end{tabular}

Table 1. Maximum percentage differences for I and II model

Finally, the first model is useful in a preliminary design phase where the one-dimensional approximation can be applied. The model can be used in an optimization tool in order to find the lighter configuration of a given thermo-structure. Since it is very simple and fast, complex optimizations characterized by a relevant number of design and constraint variables can be performed. Then significant amount of computational time can be saved adopting the proposed model instead of the Finite Element method approach.

\section{Application}

The described model has been applied to preliminary design the ceramic wing leading edge of a re-entry vehicle. This activity has been performed in the frame of a project founded by the Italian Space Agency (ASI). The aim of the project is to develop advanced reusable structures able to sustain the high thermal loads encountered by re-entry and hypersonic vehicles (Ferraiuolo et al, 2008, 2009; Glass, 2008). Previously, the wing leading edge had been sized adopting a Finite Element commercial code (ANSYS) together with a first order optimization method (Ryszard, 2006; Hackman, Richardson, 2000). In the preliminary 
design phase, a two-dimensional geometry has been considered since the aero-thermal loads do not vary significantly along the wing.

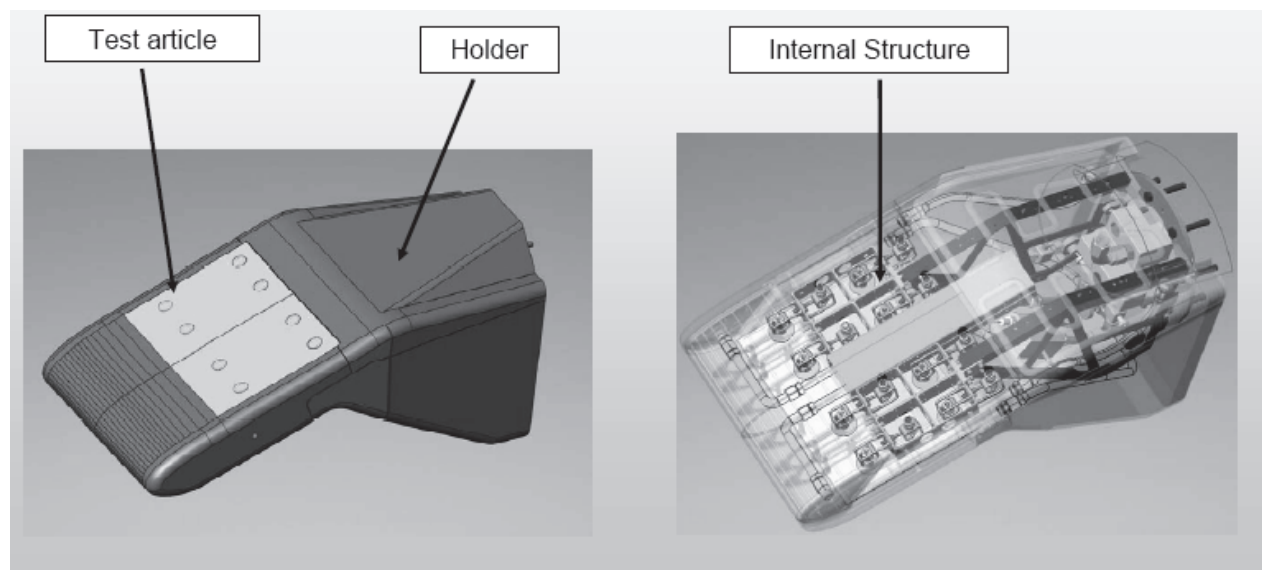

Fig. 12. Scheme of the Test Article

The components of the Test-Article are (see figure 13):

1. UHTC (Ultra High Temperature Ceramic) wing leading edge,

2. C/C panel to be joined with the UHTC WLE and the radiative shield,

3. Steel and Inconel slabs representing the internal structure of the Test Article,

4. Radiation shield used to minimize the heat transfer between the UHTC and the internal structure.

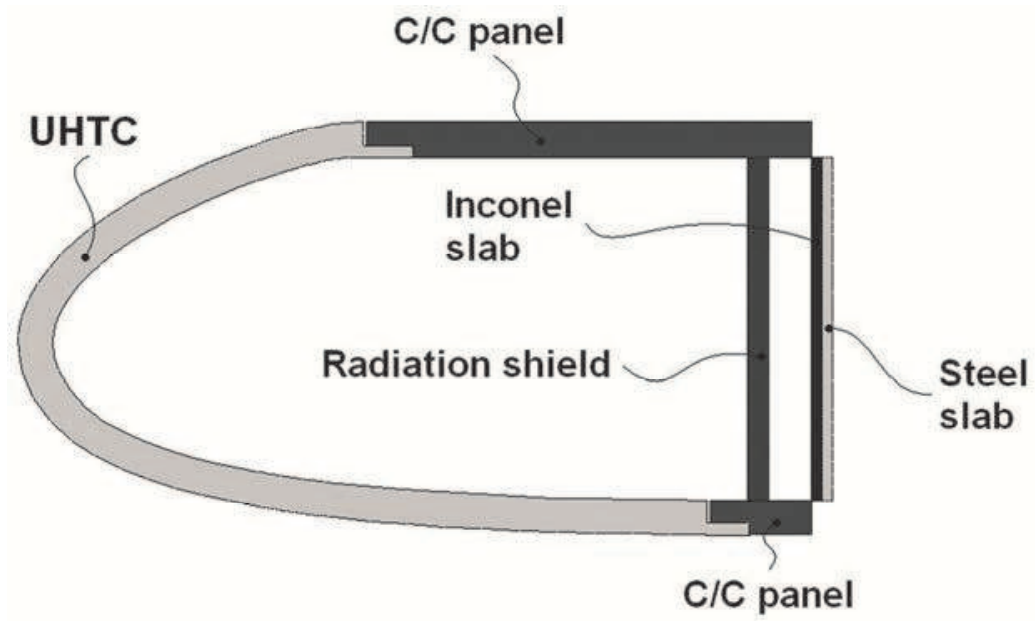

Fig. 13. 2d scheme of the internal structure of the WLE

The design variables considered for the optimization phase are:

1. UHTC WLE thickness

2. Radiation Shield Thickness 
3. UHTC material (discrete variable; 3 UHTC material have been considered in the optimization phase).

The constraint variables are:

1. Limit use temperatures for the UHTC and the radiation shield,

2. Maximum temperature of the steel slab that must not exceed $430 \mathrm{~K}$ (this constraint has been chosen since measurement devices in the steel slab cannot operate at a greater temperature value).

The objective is to minimize the weight of the structure.

The result of the optimization is an almost constant UHTC thickness of $10 \mathrm{~mm}$ and a $8 \mathrm{~mm}$ thickness for the radiation shield. The time needed to perform that optimization was about 160 hours. Figure illustrates the 3D final configuration of the UHTC wing leading edge.

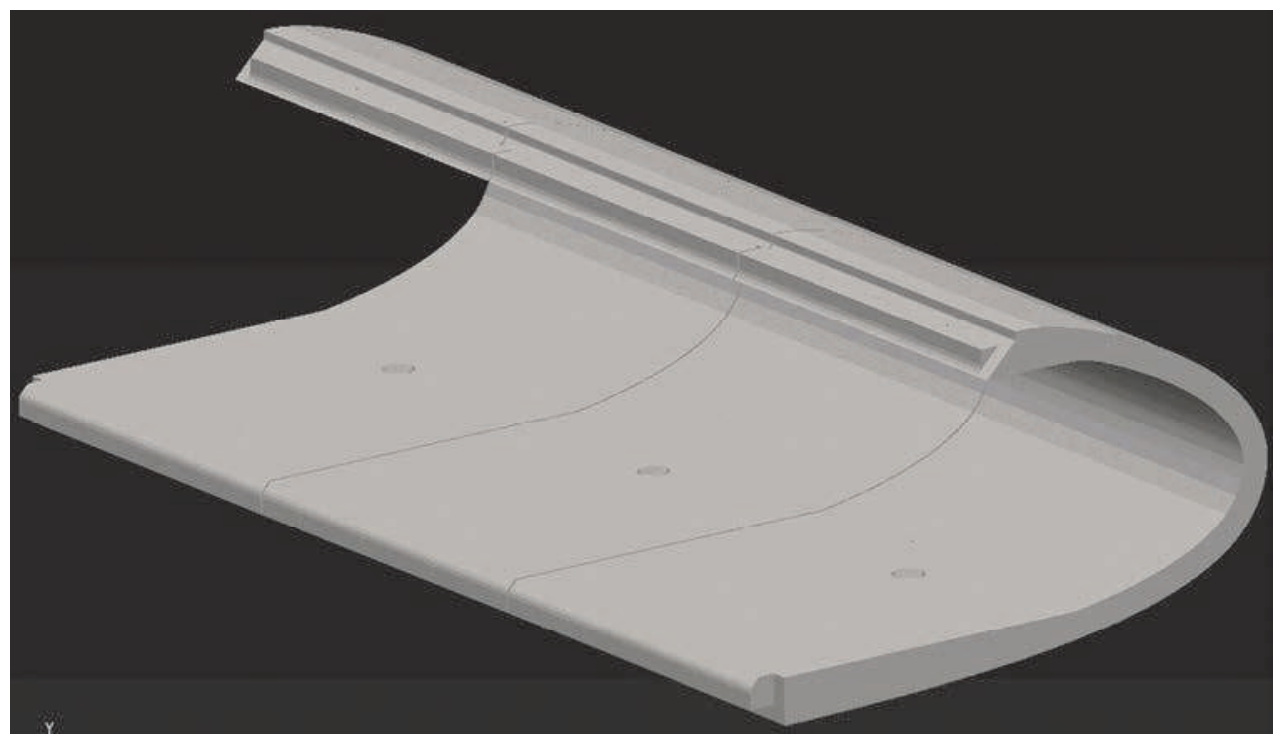

Fig. 14. 3d scheme of the WLE

\subsection{Optimization of The WLE with the proposed model}

The model described in paragraph II has been adopted to preliminary design the above described Wing Leading edge. An optimization code (MODEFRONTIER) has been used in order to perform the optimizations. The model has been implemented in Excel and then in MODEFRONTIER.

Figure 15 illustrates where the proposed model has been used. In particular, in the "* 1 " rectangles the model considering the internal radiation has been adopted; in the "*3" one the model considering only the external radiation has been adopted; the "* 4 " rectangle refers to the double-layered model and the "*2" one refers to a numeric model able to evaluate the thermal and the structural responses of multi-layered structure subjected to aerodynamic heating (Ferraiuolo et. al, 2008).

The structural sizing has been performed only in rectangles "*2" since they include the junction between The UHTC leading edge and the C/C panel which is more critical from a structural point of view (Blosser, Mcwithey, 1983, Thomas, 2002;Milos, Squire, 1999). 
Structural sizing on the remaining areas will be performed in a subsequent detailed design phase.

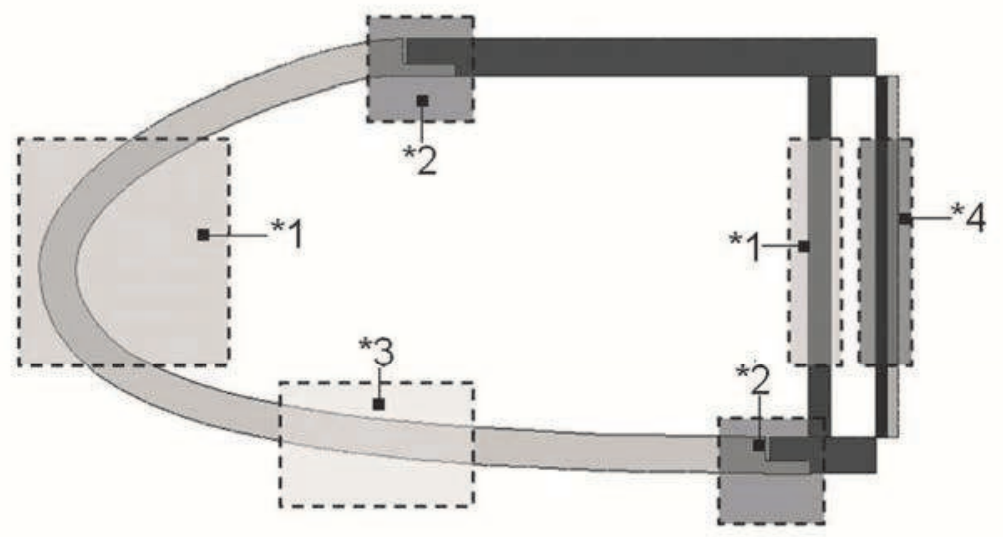

Fig. 15. Models adopted for the preliminary design

The optimization phase has been enriched considering the possibility to change the UHTC material. Then, a discrete design variable has been added in MODEFORNTIER. Figure 16 illustrates the scheme built in MODFRONTIER.

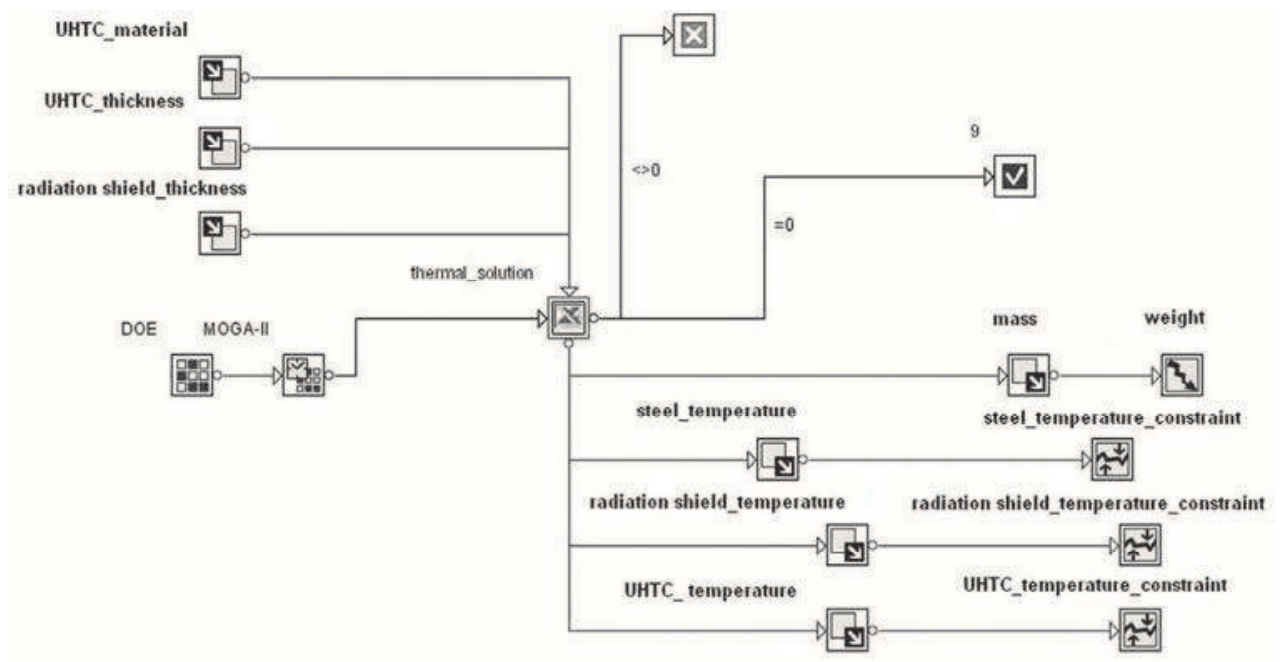

Fig. 16. Modefrontier optimization scheme

Ten points have been chosen for the optimization of the WLE (see figure 17).

A gradient based method has been chosen to perform the optimization. The time needed to perform the optimization is 20 hours, 8 times smaller than the time needed adopting finite element codes. The outputs of the optimizations are summarized in tables 2,3 and 4. 


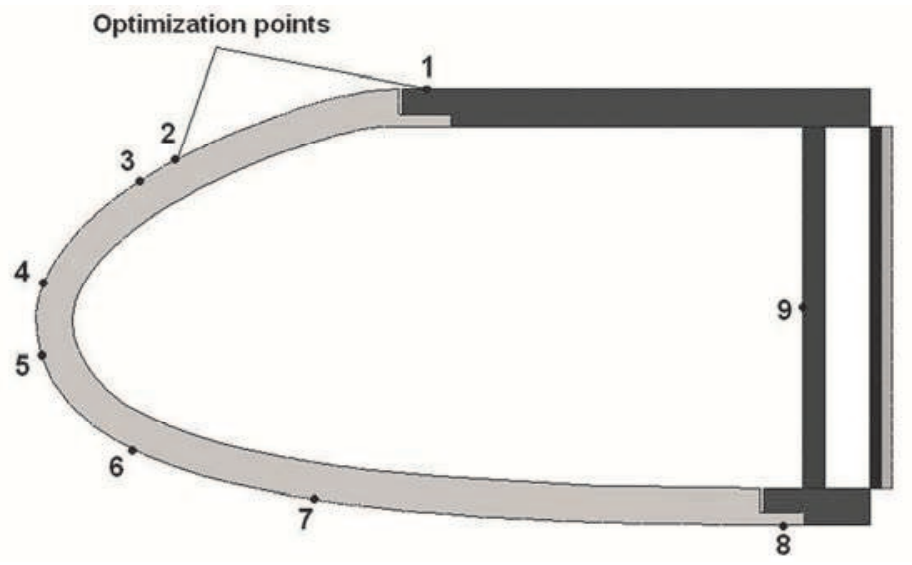

Fig. 17. Optimization points

\begin{tabular}{|c|c|c|}
\hline Points & Optimized thickness $(\mathrm{mm})$ & Material Number \\
\hline 2 & 9 & 3 \\
\hline 3 & 8.5 & 1 \\
\hline 4 & 8 & 1 \\
\hline 5 & 8 & 1 \\
\hline 6 & 9.5 & 1 \\
\hline 7 & 10 & 1 \\
\hline
\end{tabular}

Table 2. Optimized thicknesses and materials- points 2-7

\begin{tabular}{|c|c|c|c|}
\hline Points & UHTC Thickness $(\mathrm{mm})$ & C/C Thickness $(\mathrm{mm})$ & Material number \\
\hline 1 & 4 & 5 & 3 \\
\hline 8 & 4.1 & 5.9 & 1 \\
\hline
\end{tabular}

Table 3. Optimized thicknesses and materials- points 1 and 8

\begin{tabular}{|c|c|}
\hline Point & Optimized thickness \\
\hline 9 & 8 \\
\hline
\end{tabular}

Table 4. Optimized thickness - point 9

Interpolating the optimized thicknesses along the wing leading edge, the following configuration is obtained (figure 18):

The final weight is $12 \%$ less than the starting configuration. All the optimized thicknesses are less than $10 \mathrm{~mm}$, except for the point 7. The material 3 chosen for the upper portion of the wing leading edge, is characterized by a smaller density and Temperature limit use with respect to materials 1 and 2 . The design of the connection between the UHTC WLE and the $\mathrm{C} / \mathrm{C}$ panel will be performed in the detailed design phase [19]. 


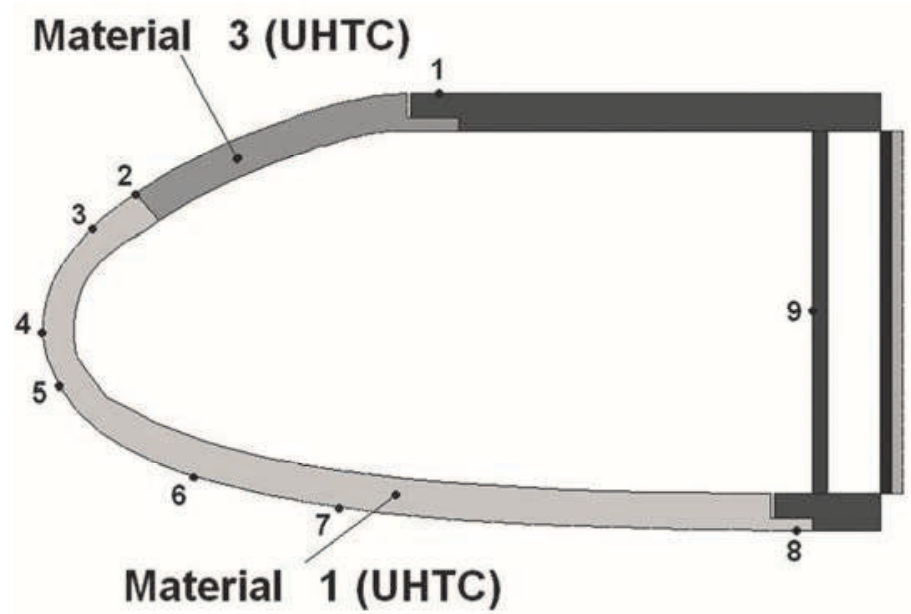

Fig. 18. Optimized configuration

Figure 19 illustrates the linearized thickness distribution for that starting and the optimized configuration. the black area highlights the weight saving amount obtained by adopting the numeric-analytic model proposed.

\section{linearized thickness distribution}

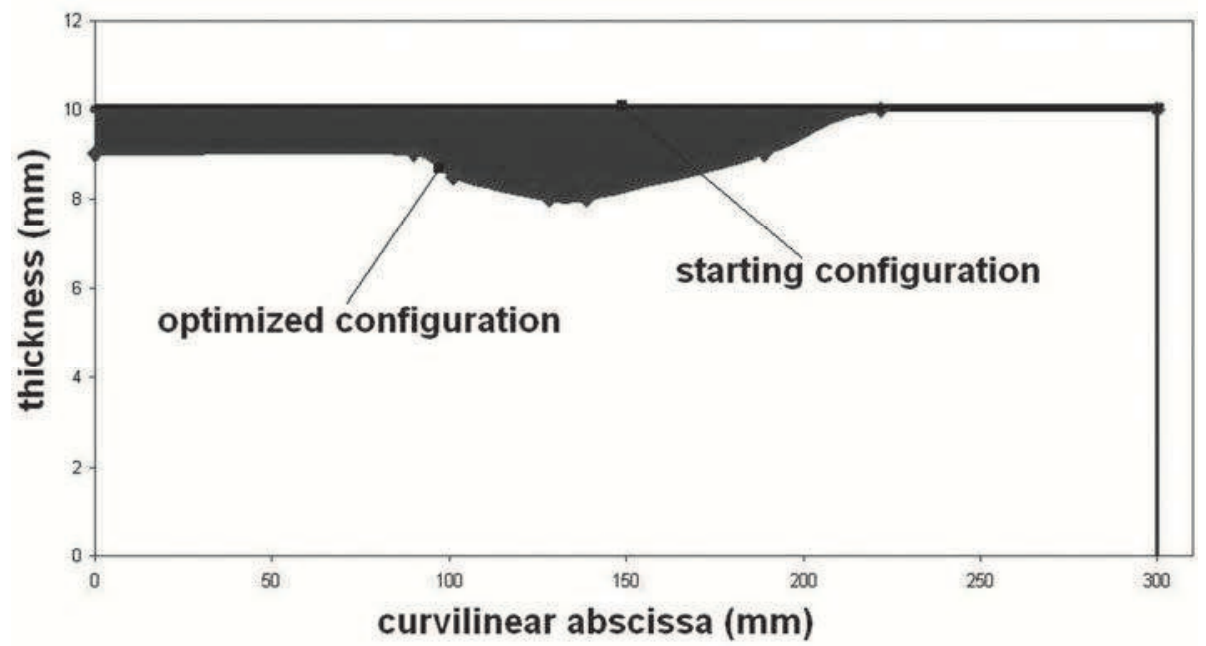

Fig. 19. Wing leading edge - linearized thickness distribution

A finite element model representing the optimized configuration has been built in order to compare the results obtained by means of the proposed model and the results obtained by means of the Finite Element Method.

Table 5 contains the temperature values evaluated at the time instant characterized by the maximum heat flux. 


\begin{tabular}{|c|c|c|c|}
\hline Points & $\begin{array}{c}\text { Temperature (K) } \\
\text { Fem model (2D) }\end{array}$ & $\begin{array}{c}\text { Temperature (K) } \\
\text { Proposed model (1D) }\end{array}$ & Percentage difference \\
\hline 1 & 766.5 & 786.24 & -4 \\
\hline 2 & 1351.1 & 1403.9 & -4.9 \\
\hline 3 & 1397.6 & 1483.9 & -5.9 \\
\hline 4 & 1496.6 & 1557.7 & -5 \\
\hline 5 & 1533.7 & 1582.9 & -3.9 \\
\hline 6 & 1633.6 & 1713.1 & -5.9 \\
\hline 7 & 1613.0 & 1696.1 & -6.2 \\
\hline 8 & 956.4 & 983.7 & -4 \\
\hline 9 & 712.2 & 734.1 & -5 \\
\hline
\end{tabular}

Table 5. FEM and proposed model results-Temperature

Table 6 contains the principal stress S1 values for points 1 and 8 .

\begin{tabular}{|c|c|c|c|}
\hline Points & $\begin{array}{c}\text { Stress S1 (MPa) } \\
\text { FEM model (2D) }\end{array}$ & $\begin{array}{c}\text { Stress S1 (MPa) } \\
\text { Proposed model (2D) }\end{array}$ & $\begin{array}{c}\text { Percentage } \\
\text { difference }\end{array}$ \\
\hline 1 & 202 & 183.8 & -9 \\
\hline 8 & 185 & 166.9 & -9.8 \\
\hline
\end{tabular}

Table 6. FEM and proposed model results - stress values

The proposed model overestimates the temperature values with respect to the Finite element model. The maximum percentage difference is always less than $10 \%$. As a consequence the presented numeric-analytic model is applicable to two-dimensional geometries where the heat transfer contribution in a direction is negligible with respect to the other ones.

\section{Conclusion}

A simplified numeric-analytic one-dimensional model able to simulate the thermal behavior of thermal structures has been developed. Radiation and thermal properties non linearities have been taken into account. The model is useful to minimize the computational time needed to perform the preliminary design phase of structural components of re-entry or hypersonic vehicles. The time saving is possible since the proposed model is very simple and does not foresee a spatial discretization of the geometry. Then complex optimizations characterized by several design constraints, variables and objectives can be performed in a reasonable amount of time. The results obtained with the simplified model have been compared with the results obtained by means of the finite element method giving good results (the maximum percentage difference never exceeds $20 \%$ ).

The model has been applied to preliminary design the ceramic wing leading edge of a reentry vehicle allowing to save $12 \%$ of the weight with a computational time 8 times smaller with respect to the previous optimization performed on a two-dimensional finite element model. A thermostructural finite element analysis performed on the optimized configuration has demonstrated a good accordance between the results obtained with the proposed model and those obtained with the two-dimensional Finite element method. 
Finally, the proposed simplified approach is well suited for thermal protection systems and hot structures where the one-dimensional assumption is acceptable. Particular attention must be paid on curved geometries like the wing leading edge where the approach can be used only in certain areas.

\section{References}

Thornton Earl A. Thermal Structures for Aerospace Applications 2nd ed., AIAA series, 1996, pp. 103-118, Chap. 4

Kelly H. Neale, D.R. Rummler and R. Jackson. Research in Structures and Materials for Future Space Transportation Systems - An Overview, Journal of Spacecrafts and Rockets, 20, pp.89-96, 1983.

Shih, P.K., Prunty, J., Mueller, R.N. Thermostructural Concepts for Hypervelocity Vehicles, AIAA Paper 88-2295, April 1988

Daryabeigi K., Thermal Analysis and Design Optimization of Multilayer Insulation for Re-entry Aerodynamic Heating, , Journal of Spacecraft and Rockets, Vol.39, No.4, August 2002

Poteet C., Hasan Abu-Khajeel, Su-Yuen Hsu, Preliminary Thermal-Mechanical Sizing of a Metallic Thermal Protection System, Journal of Spacecraft and Rockets, Vol. 41, No. 2, March-April 2004

Kunihiko O., Thermal analysis of the thermal protection system for the re-entry vehicle, Computer methods in applied mechanics and engineering, 1998

J. Crank, The Mathematics of Diffusion, Oxford Science Publication, 1979

Syed M. , A. F. M. Arif, and Mostafa H. Sharqawy. Thermal Analysis and Optimization of Orthotropic Pin Fins: A Closed-Form Analytical Solution, J. Heat Transfer 132, 031301 (2010) (8 pages), 2010

Necati, OzisiK. Heat conduction, second edition, , John Wiley and sons, 1993

ANSYS ${ }^{\circledR}$ and ANSYS Workbench ${ }^{\circledR}$ Reference Documentation, Version 12.0

Ferraiuolo M., Riccio A., Gigliotti M., Tescione D., Gardi R., Marino G. Thermostructural design of a Flying Winglet Experimental Structure for the EXPERT Re-entry Test, Journal of Heat Transfer, ASME, July 2009, Vol. 131

Ferraiuolo M., Riccio A.., Tescione D., Gardi R., Marino G. Contact Sensitivity Analysis of a coupling pin for the Nose cap of a launch reentry vehicle, JBIS, 61, pp.14-19, 2008.

Glass D. CMC-based hot structures, 1st Workshop on Science and Technology of UHTC-Based Hot Structures, CIRA, Capua, Italy October 28-29, 2008

Ryszard K. Sensitivity analysis and shape optimization for transient heat conduction with radiation, International Journal of Heat and Mass Transfer 49 (2006) 2033-2043, 2006

Hackman L. E., Richardson J. E. Design Optimization of Aircraft Structures with Thermal Gradients, Journal of aircraft, 2000

Ferraiuolo M., Riccio A., Tescione D., Gigliotti M. A fast procedure for optimizing Thermal Protection Systems for Re-entry vehicles, JBIS Vol. 61 pp. 478-486, 2008

Blosser M. L., Mcwithey R., "Theoretical Basis for Design of Thermal-Stress-Free Fasteners", NASA Technical Paper 2226 December 1983

Thomas J.D. Design and Analysis of UHTC Leading Edge Attachment, NASA/CR 2002-211505, 2002

Milos F., Squire T. H. Thermostructural Analysis of X-34 Wing Leading-Edge Tile Thermal Protection System, Journal of Spacecraft and Rockets Vol. 36, No. 2, March-April 1999 


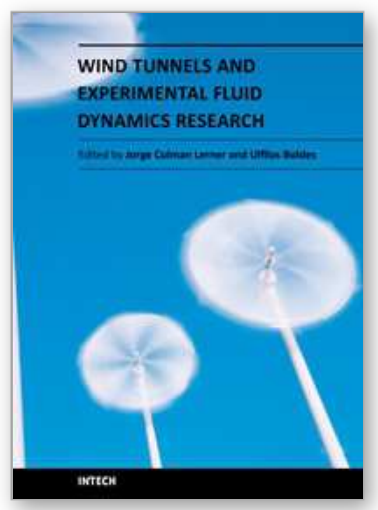

\author{
Wind Tunnels and Experimental Fluid Dynamics Research \\ Edited by Prof. Jorge Colman Lerner
}

ISBN 978-953-307-623-2

Hard cover, 709 pages

Publisher InTech

Published online 27, July, 2011

Published in print edition July, 2011

The book â€œWind Tunnels and Experimental Fluid Dynamics Researchâ€ is comprised of 33 chapters divided in five sections. The first 12 chapters discuss wind tunnel facilities and experiments in incompressible flow, while the next seven chapters deal with building dynamics, flow control and fluid mechanics. Third section of the book is dedicated to chapters discussing aerodynamic field measurements and real full scale analysis (chapters 20-22). Chapters in the last two sections deal with turbulent structure analysis (chapters 23-25) and wind tunnels in compressible flow (chapters 26-33). Contributions from a large number of international experts make this publication a highly valuable resource in wind tunnels and fluid dynamics field of research.

\title{
How to reference
}

In order to correctly reference this scholarly work, feel free to copy and paste the following:

Michele Ferraiuolo and Oronzio Manca (2011). A New Methodology to Preliminary Design Structural Components of Re-Entry and Hypersonic Vehicles, Wind Tunnels and Experimental Fluid Dynamics Research, Prof. Jorge Colman Lerner (Ed.), ISBN: 978-953-307-623-2, InTech, Available from:

http://www.intechopen.com/books/wind-tunnels-and-experimental-fluid-dynamics-research/a-newmethodology-to-preliminary-design-structural-components-of-re-entry-and-hypersonic-vehicles

\section{INTECH}

open science | open minds

\section{InTech Europe}

University Campus STeP Ri

Slavka Krautzeka 83/A

51000 Rijeka, Croatia

Phone: +385 (51) 770447

Fax: +385 (51) 686166

www.intechopen.com

\section{InTech China}

Unit 405, Office Block, Hotel Equatorial Shanghai

No.65, Yan An Road (West), Shanghai, 200040, China

中国上海市延安西路65号上海国际贵都大饭店办公楼 405 单元

Phone: +86-21-62489820

Fax: +86-21-62489821 
(C) 2011 The Author(s). Licensee IntechOpen. This chapter is distributed under the terms of the Creative Commons Attribution-NonCommercialShareAlike-3.0 License, which permits use, distribution and reproduction for non-commercial purposes, provided the original is properly cited and derivative works building on this content are distributed under the same license. 